\title{
Hypercoagulability in the Context of Pre-Eclampsia: Case-Control Study at the Laquintinie Douala Hospital (Cameroon)
}

\author{
Henri Essome ${ }^{1,2 *}$, Marie Solange Ndom Idjem¹, Théophile Nana Njamen33, \\ Thomas Egbe Obinchemti ${ }^{3}$, Merlin Boten" ${ }^{1}$, Grace Tocki Toutou${ }^{4}$, Grégory Eddie Halle ${ }^{3}$, \\ Guy Pascal Ngaba ${ }^{2}$, Pascal Foumane ${ }^{5}$
}

${ }^{1}$ Laquintinie Douala Hospital, Douala, Cameroon

${ }^{2}$ Faculty of Medicine and Pharmaceutical Sciences of Douala, University of Douala, Douala, Cameroon

${ }^{3}$ Faculty of Health Sciences of Buea, University of Buea, Buea, Cameroon

${ }^{4}$ Kribi District Hospital, Kribi, Cameroon

${ }^{5}$ Faculty of Biomedical Sciences of Yaoundé, University of Yaoundé 1, Yaoundé, Cameroon

Email: *essometocky@yahoo.com

How to cite this paper: Essome, H., Idjem, M.S.N., Njamen, T.N., Obinchemti, T.E., Boten, M., Toutou, G.T., Halle, G.E., Ngaba, G.P. and Foumane, P. (2020) Hypercoagulability in the Context of Pre-Eclampsia: Case-Control Study at the Laquintinie Douala Hospital (Cameroon). Open Journal of $\mathrm{Ob}$ stetrics and Gynecology, 10, 1708-1727. https://doi.org/10.4236/ojog.2020.10120155

Received: November 16, 2020

Accepted: December 22, 2020

Published: December 25, 2020

Copyright (อ 2020 by author(s) and Scientific Research Publishing Inc. This work is licensed under the Creative Commons Attribution International License (CC BY 4.0).

http://creativecommons.org/licenses/by/4.0/ (c) (i) Open Access

\begin{abstract}
Introduction: Preeclampsia is one of the major causes of maternal and neonatal morbidity and mortality in the world. The complexity of its etio-pathogenesis involves, among other things, hypercoagulability, which alone accounts for about $15 \%$ of his deaths. Our objective was to study the parameters of coagulation (prothrombin level, activated cephalin time) in pregnant women with preeclampsia and non-preeclampsia at Laquintinie Hospital in Douala. Methodology: We carried out an analytical cross-sectional case-control study from November $01^{\text {st }}, 2018$ to May 31 ${ }^{\text {st }}, 2019$, in the gynecology and obstetrics department of Laquintinie Hospital in Douala. We included preeclampsia and non-preeclampsia pregnant women with a gestational age greater than or equal to 20 weeks amenorrhea. The variables of interest were age, pregnancy, parity, gestational age, marital status and body mass index, prothrombin level (PL) and activated cephalin time (ACT). Hypercoagulability was defined by the presence of at least one of the following abnormalities: PL $>100 \%$, ACT $<$ 25 seconds. Statistical tests were considered significant for a p-value $<0.05$. Results: We recruited 150 pregnant women including 50 preeclampsia matched with 100 non-preeclampsia. The majority age group in both groups was 25 30 years ( $32 \%$ versus $37 \%$ ). We found a high PL in $58 \%$ of preeclampsia versus $22 \%$ of non-preeclampsia patients $(\mathrm{p}=<0.001)$, a low PL in $8 \%$ of preeclampsia versus $0 \%$ in non-preeclampsia patients $(\mathrm{p}=0.004)$. The ACT was prolonged in $12 \%$ of the preeclampsia versus $0 \%$ in the non-preeclampsia patients $(\mathrm{p}=<0.001)$. Pregnant women with preeclampsia were 4.89 times more
\end{abstract}


likely to develop hypercoagulability than pregnant women without preeclampsia (OR 4.89; CI $2.34-10.20 ; \mathrm{p}=<0.001$ ). In linear regression, preeclampsia was significantly associated with PL (correlation coefficient $0.07 ; \mathrm{p}=$ 0.008). We did not find risk factors associated with hypercoagulability in preeclampsia. Conclusion: Our study confirms the existence of hypercoagulability associated with preeclampsia, in particular in relation to an increase in the level of prothrombin.

\section{Keywords}

Preeclampsia, Hypercoagulability, Prothrombin, Cephalin, Lacintinia

\section{Introduction}

Preeclampsia is defined as the onset of arterial hypertension (HTN) associated with proteinuria after 20 weeks of amenorrhea in a previously normal pregnant woman [1] and occurs in $2 \%$ to $7 \%$ of pregnancies [2]. According to WHO, it is a major cause of maternal and neonatal morbidity and mortality in the world (14\%) and especially in developing countries [3]. It is the third leading cause of maternal mortality, after postpartum hemorrhage and infections in Cameroon [4]. Although the exact cause of preeclampsia is not fully understood, it can be attributed to some factors including changes in placental perfusion, endothelial dysfunction, fibrin deposition, inflammation, and hypercoagulability [5] [6]. Hypercoagulability is an imbalance between coagulation and fibrinolysis activities leading to the development of multiple thrombi and the rapid consumption of platelets, prothrombin, fibrinogen and other coagulation factors [7] [8] and is thought to be responsible for around $15 \%$ of maternal deaths due to preeclampsia [9].

Abnormal enhancement of coagulation activity is implicated in the pathogenesis of preeclampsia, as suggested by the increased frequency of venous thromboembolic events, thrombotic placental abnormalities and thrombin generation in this population [10] [11]. This state of hypercoagulability is described in the literature as being more important in preeclampsia compared to normal pregnancies [12] [13] [14]. In France in 2013, a study found the level of prothrombin higher in preeclampsia during pregnancy, childbirth and postpartum [12]. In China, Han et al. in 2014 found that during the third trimester, pregnant women with preeclampsia exhibited a state of higher hypercoagulability with the prolongation of activated partial thromboplastin time (APTT) and thrombin time (TT), increased D-dimer and mean platelet volume [13]. In Sudan, Husham et al. in 2016 found that women with severe preeclampsia had significantly higher levels of thrombin-activatable fibrinolysis inhibitor (TAFI), plasminogen activator inhibitor (PAI) 1, and a significantly lower level of PAI-2 [14].

In Cameroon, several studies have been done on preeclampsia, but data on hypercoagulability and preeclampsia are scarce. In order to improve the know- 
ledge and the management of hypercoagulability associated with preeclampsia in Cameroon, we conducted a preliminary study whose aim was to evaluate the coagulation of pregnant women with preeclampsia at Laquintinie hospital in Douala through the level of prothrombin and the activated cephalin time.

\section{Methodology}

1) Type of study: This was a cross-sectional analytical case-control study.

2) Period, Duration and Place of Study: Our study took place from November $01^{\text {st }}, 2018$ to May $31^{\text {st }}, 2019$ (i.e. 07 months) in the gynecology and obstetrics department of Laquintinie Hospital in Douala.

3) Study population: It consisted of preeclampsia and non-preeclampsia pregnant women received during our study period.

a) Inclusion Criteria

We included in our study pregnant women from our study population who gave their informed consent without distinction of age, pregnancy or parity.

Preeclampsia group

Pregnant women with moderate or severe preeclampsia without distinction of gestational age.

Non-preeclampsia group

- Absence of preeclampsia

- Gestational age greater than or equal to 20 weeks of amenorrhea.

\section{b) Exclusion Criteria}

Were excluded from our study;

Common exclusions: smoking, chronic renal failure, chronic liver disease, blood crass disorders, treatment with anti-vitamin $\mathrm{K}$.

Specific exclusions: Non-preeclampsia group: risk factors for preeclampsia (previous diabetes, chronic hypertension, anti-phospholipid syndrome, lupus, history of preeclampsia), gestational hypertension.

4) Sampling: We performed a convenient, consecutive and non-exhaustive sampling given the lack of data on the prevalence of increased prothrombin levels and activated cephalin time in both preeclampsia and normal pregnancies.

\section{5) Procedure}

\section{a) Administrative procedures}

The study protocol had been submitted to the Institutional Research Ethics Committee for Human Health at the University of Douala. An ethical clearance $\mathrm{N}^{\circ} 1727$ CEI-Udo/02/2019/T was issued to us before the start of data collection for our study. This was done with respect for confidentiality, with collection sheets that were anonymous and the results used for scientific purposes. We also obtained the authorizations from the director of Laquintinie Hospital.

\section{b) Collection of data}

After obtaining informed consent following the explanations of the study, the data was collected using a structured data sheet. The variables of interest were;

1) Socio-demographic: Age, marital status (single, married,), gestational age in week of amenorrhea, gestation and parity. 
2) Medical (History): Hypertension, diabetes, addiction to tobacco, thromboembolic disease, preeclampsia, autoimmune disease, hematological conditions, chronic liver disease, chronic kidney disease, anticoagulant use. The positivity or negativity of this history was made on the basis of documentation at the medical record level.

3) Physical: a) Anthropometric and hemodynamic parameters.

- Weight (kg), measured using a CAMRY brand scale (Hong Kong, China); the patient standing and barefoot, upright on the scale.

- Height (in $\mathrm{cm}$ ), measured with a measuring rod, the patient with bare feet standing upright with his head horizontal.

- The Body Mass Index (in $\mathrm{kg} / \mathrm{m}^{2}$ ) was obtained using the 2 previous measurements by Quételet's formula (the ratio of weight in $\mathrm{kg}$ to the square of the height in $\mathrm{m})$. Interpretation were as follows: Normal weight (18.5 - 24.9), overweight (25 - 29.9), Obesity grade 1 (30 - 34.9), Obesity grade 2 (35 39.9), morbid obesity ( $\geq 40)$.

- Blood pressure (in mmhg): after 10 minutes of rest, it was measured in both arms. This measurement was made using electronic blood pressure monitors from OMRON (Kyoto, Japan). Anyone with BP $\geq 140 / 90$ mm hg was considered hypertensive.

b) Urinary dipstick (for proteinuria testing): It was done using MISSION brand urine strips LOT no.: URS8060151 only in non-preeclampsia patients. Proteinuria was said to be significant from two crosses.

4) Biological data: a) parameters of hemostasis: We explored the coagulation phase of hemostasis through quick time (QT), prothrombin level (PL) and activated cephalin time (ACT).

The activated cephalin time (ACT) consists of activating the intrinsic pathway of coagulation and explores the factors of the contact system (FXll and FXI, high molecular weight kininogen, prekallikrein), of the anti-hemophilic complex (FIX, FVll 1), of the complex prothrombinase (FX, FV), prothrombin (FII) and fibrinogen (ex-FI).

The Prothrombin time (PT) consists in measuring the time elapsed until fibrin formation after addition to citrated plasma of an excess of calcium thromboplastin containing tissue factor, phospholipids and calcium. It is customary to express the prothrombin time as a percentage after calibration. The test is improperly called prothrombin level (PL). PT explores factors VII, X, V, II and fibrinogen.

a) Place of sample collection

Samples were taken in obstetrical emergencies, in antenatal care, or in the pathological pregnancy department by venipuncture at the fold of the elbow.

b) Sample collection and analysis

For each patient, $5 \mathrm{ml}$ of blood was taken in 01 citrated tube for the determination of QT, PL, INR and ACT. And the analysis was carried out within 2 hours, after centrifugation at most 15 minutes after sampling, to obtain a plasma poor in platelets by a semi-automatic coagulometer of the BIO SOLEA 2 brand, 
serial number: $026020-00345$ in the laboratory of the Laquintinie hospital as follows:

- Analysis of QT, PL and INR

We used the BIO-PT reagents from the Biolabo laboratory batch no. 021828A consisting of R1 (thromboplastin) and R2 (reconstitution buffer).

Preparation of the working reagent: $4 \mathrm{ml}$ of $\mathrm{R} 2$ solution in a bottle of R1. Homogenize then pre-incubate at least $15 \mathrm{~min}$ at $37^{\circ}$.

Analysis proper: $0.1 \mathrm{ml}$ of plasma is taken, placed in a cuvette containing a bead and incubated for 2 minutes. Then $0.2 \mathrm{ml}$ of the working reagent is added to it. The automatic time count starts when the working reagent is added and stops when the clot is formed, thus obtaining the values of QT in seconds, PL in percentage and INR.

Normal values: TQ 12 - 14 s, TP 70\% - 100\%, INR 1.

- ACT analysis

We used the BIO-CK reagent from the laboratory biolabo lot no: 031854A consisting of R1 (kaolin cephalin), $0.025 \mathrm{M}$ calcium chloride and distilled water.

Preparation of the working reagent: $3 \mathrm{ml}$ of distilled water in a flask of $\mathrm{R} 1$ then homogenized.

Analysis proper: pre-incubate $0.025 \mathrm{M}$ calcium chloride at $37^{\circ} .0 .1 \mathrm{ml}$ of the working reagent is placed in a cuvette containing a bead, then $0.1 \mathrm{ml}$ of the plasma is added to it. The solution is stirred and incubated for $3 \mathrm{~min}$. Then 0.1 $\mathrm{ml}$ of calcium chloride is added to it. The automatic time count starts when the calcium chloride is added and stops when the clot forms. So we get the ACT value in seconds.

Normal value: 25 - $40 \mathrm{~s}$.

\section{6) Statistical analysis}

The data collected was recorded, entered and analyzed using Epi Info 7, Excel 2013 and the software Epi Data 3.1 (Lauritzen, Denmark). Quantitative variables were grouped together as a mean with standard deviation. Qualitative variables in the form of numbers and percentages. The comparison of the qualitative values was made using the Chi-square test and the quantitative variables using the student $\mathrm{t}$ test. The calculation of the odds ratios and their $95 \%$ confidence interval was only done when comparing the biological parameters of the two groups during univariate analysis. Multiple linear regression models were performed, in which PL and ACT levels were dependent variables and age, parity, gestational age, BMI, and preeclampsia were the independent predictors of interest. The $\mathrm{p}$-value was significant if it is less than 0.05 .

\section{Results}

We approached 187 pregnant women, and retained 150 (Figure 1).

\subsection{General Characteristics of the Study Population}

The ages varied from 16 to 40 years old. The mean age of preeclampsia was 27.80 
\pm 5.80 and $29.05 \pm 5.29$ in non-preeclampsia patients without a statistically significant difference. Preeclampsia and non-preeclampsia drugs were more represented in the $25-30$ years age group, respectively $32 \%$ versus $37 \%$ without statistically significant difference. Singles were in majority in both groups, $68 \%$ in preeclampsia and $62 \%$ in non-preeclampsia patients without statistically significant difference (Table 1).

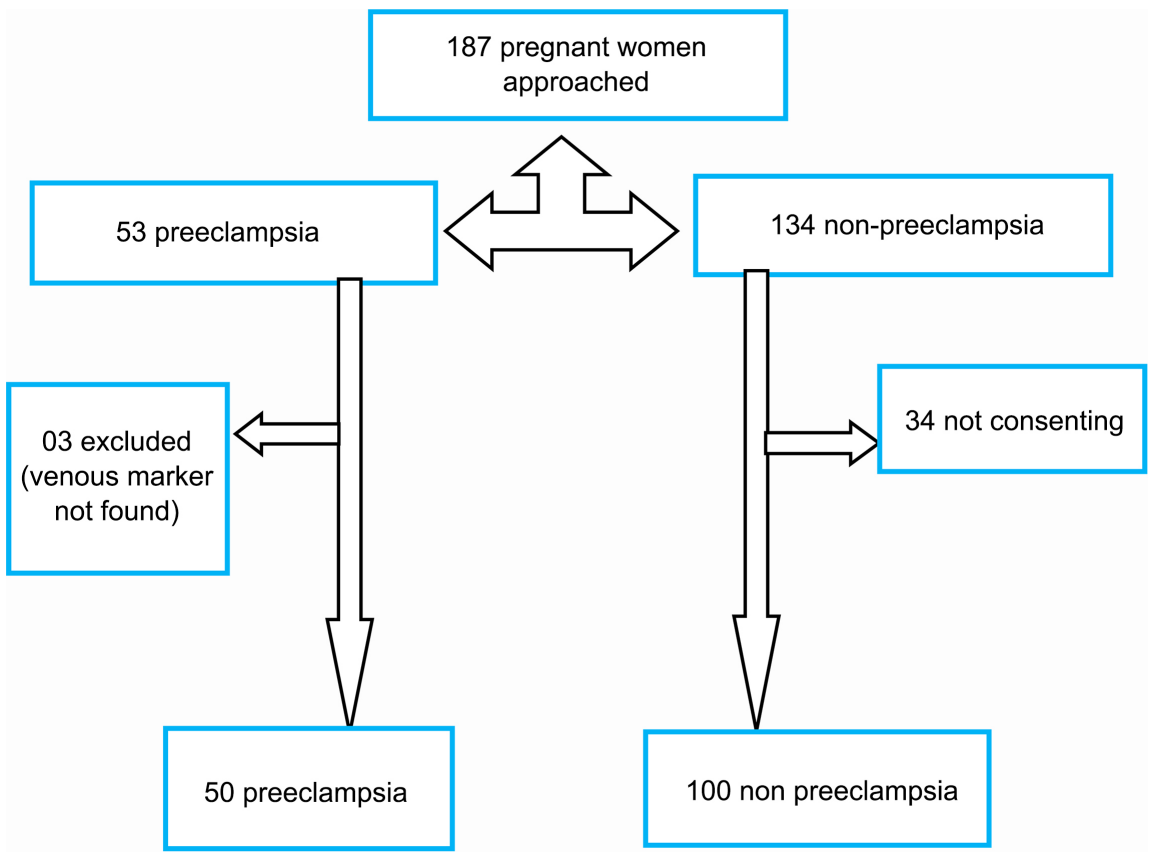

Figure 1. Process of recruiting study participants.

Table 1. Socio-demographic characteristics of our population.

\begin{tabular}{cccc}
\hline Variables & $\begin{array}{c}\text { Pre-eclampsia } \\
\mathrm{N}=50 \\
\mathrm{n}(\%)\end{array}$ & $\begin{array}{c}\text { Normal pregnant women } \\
\mathrm{N}=100 \\
\mathrm{n}(\%)\end{array}$ & $\mathrm{P}$ \\
\hline Age (years) & & & \\
Mean \pm standard deviation & $27.80 \pm 5.80$ & $29.05 \pm 5.29$ & 0.189 \\
{$[15-20]$} & $4(8)$ & $2(2)$ & 0.077 \\
{$[20-25]$} & $9(18)$ & $22(22)$ & 0.568 \\
{$[25-30]$} & $16(32)$ & $37(37)$ & 0.545 \\
{$[30-35]$} & $12(24)$ & $18(18)$ & 0.386 \\
{$[35-40]$} & $8(16)$ & $17(17)$ & 0.876 \\
{$[40-45]$} & $1(2)$ & $4(4)$ & 0.520 \\
Marital status & & & \\
Single & $34(68)$ & $66(66)$ & 0.806 \\
Married & $16(32)$ & $34(34)$ & 0.806 \\
\hline
\end{tabular}


The mean gravidity was $2.66 \pm 1.45$ in the preeclampsia and $2.82 \pm 1.76$ in the non-preeclampsia patients without a statistically significant difference, with the extremes of 1 and 8 . The paucigravid were the most common in preeclampsia (40\%) and primigravid in non-preeclampsia patients (34\%). The mean parity of the preeclampsia was $1.26 \pm 1.30$ and $1.37 \pm 1.42$ in the non-preeclampsia, without a statistically significant difference, with the extremes of 0 and 5 . The nulliparas were majority in both groups (Table 2).

The mean gestational age in preeclampsia patients was $36.16 \pm 3.41$ and 33.43 \pm 5.61 in non-preeclampsia patients with a statistically significant difference $(\mathrm{p}=$ $0.047)$.

The mean body mass index in preeclampsia patients was $31.16 \pm 4.71$ and $30.23 \pm 4.73$ in non-preeclampsia patients without a statistically significant difference. Pregnant women with grade 1 obesity were predominant among those with preeclampsia ( $40 \%$ versus $16 \%$ ) with a statistically significant difference ( $\mathrm{p}$ $=0.001)$. Grade 2 obesity affected $21 \%$ of non-preeclampsia versus $6 \%$ of preeclampsia patients with a statistically significant difference $(\mathrm{p}=0.018)$ (Table 3$)$.

\subsection{Biological Parameters}

A high PL was found in $22 \%$ and a normal PL in $78 \%$ of pregnant women without preeclampsia. The ACT of pregnant women without preeclampsia was $100 \%$ normal (Figure 2 and Figure 3 ).

Table 2. Obstetric history of our population.

\begin{tabular}{|c|c|c|c|}
\hline Variables & $\begin{array}{l}\text { Preeclampsia } \\
\qquad \begin{array}{c}\mathrm{N}=50 \\
\mathrm{n}(\%)\end{array}\end{array}$ & $\begin{array}{l}\text { Normal pregnant women } \\
\qquad \begin{array}{c}\mathrm{N}=100 \\
\mathrm{n}(\%)\end{array}\end{array}$ & $\mathrm{P}$ \\
\hline \multicolumn{4}{|l|}{ Gravidity } \\
\hline Mean \pm standard deviation & $2.66 \pm 1.45$ & $2.82 \pm 1.76$ & 0.579 \\
\hline Primigravid & $17(34)$ & $34(34)$ & 1.000 \\
\hline Paucigravid & $20(40)$ & $32(32)$ & 0.331 \\
\hline Multigravid & $13(26)$ & $30(30)$ & 0.609 \\
\hline Grand multigravid & $0(0)$ & $4(4)$ & 0.151 \\
\hline \multicolumn{4}{|l|}{ Parity } \\
\hline Mean \pm standard deviation & $1.26 \pm 1.30$ & $1.37 \pm 1.42$ & 0.647 \\
\hline Nulliparous & $21(42)$ & $39(39)$ & 0.723 \\
\hline Primiparous & $7(14)$ & $22(22)$ & 0.242 \\
\hline Pauciparous & $18(36)$ & $26(26)$ & 0.204 \\
\hline Multiparous & $4(8)$ & $13(13)$ & 0.362 \\
\hline
\end{tabular}


Table 3. Gestational age and Body mass index in our population.

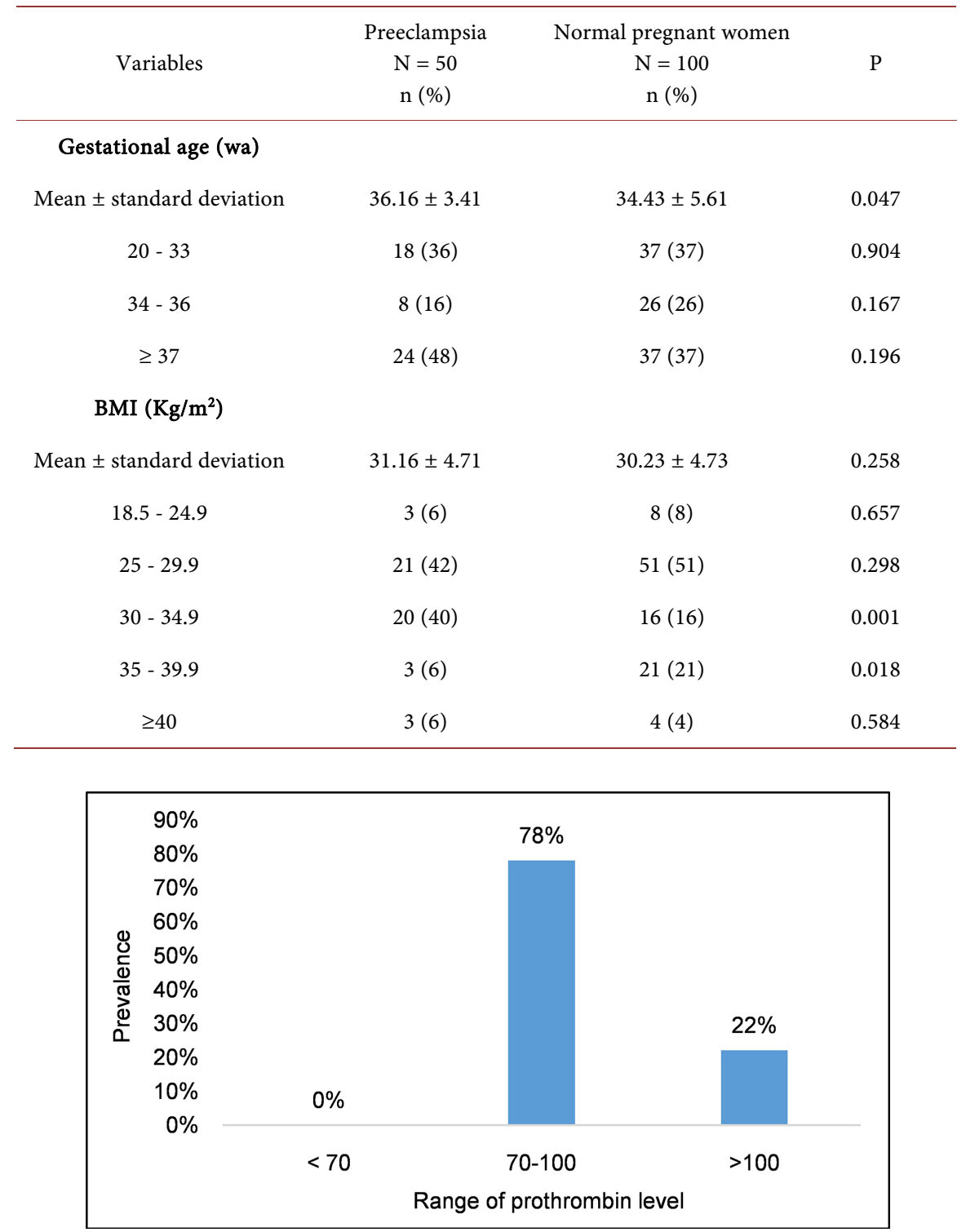

Figure 2. Prothrombin level in normal pregnant women.

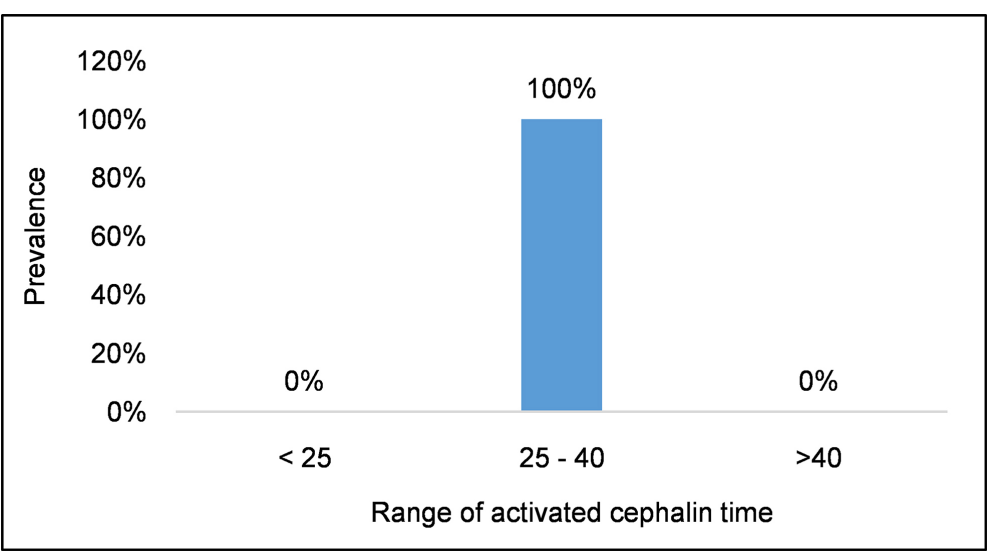

Figure 3. Activated partial thromboplastin time in normal pregnant women. 
1) Non-preeclampsia pregnant women

- Prothrombin level (PL)

- Activated Cephalin Time (ACT)

The ACT of non-preeclampsia pregnant women was 100\% normal.

Pregnant women with preeclampsia had a low PT of $8 \%$, a normal PT of $34 \%$ and a high PT of $58 \%$. Pregnant women with preeclampsia had normal TCA $88 \%$ and elevated TCA 12\% (Figure 4 and Figure 5).

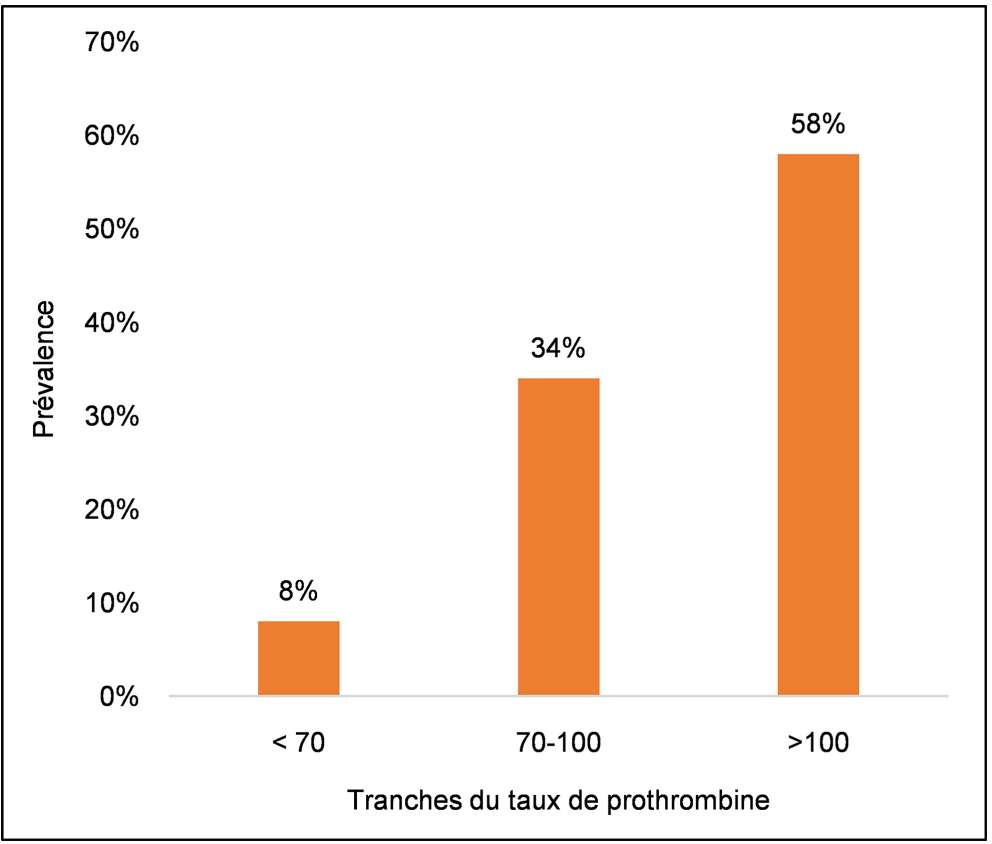

Figure 4. Prothrombin level of preeclampsia drugs.

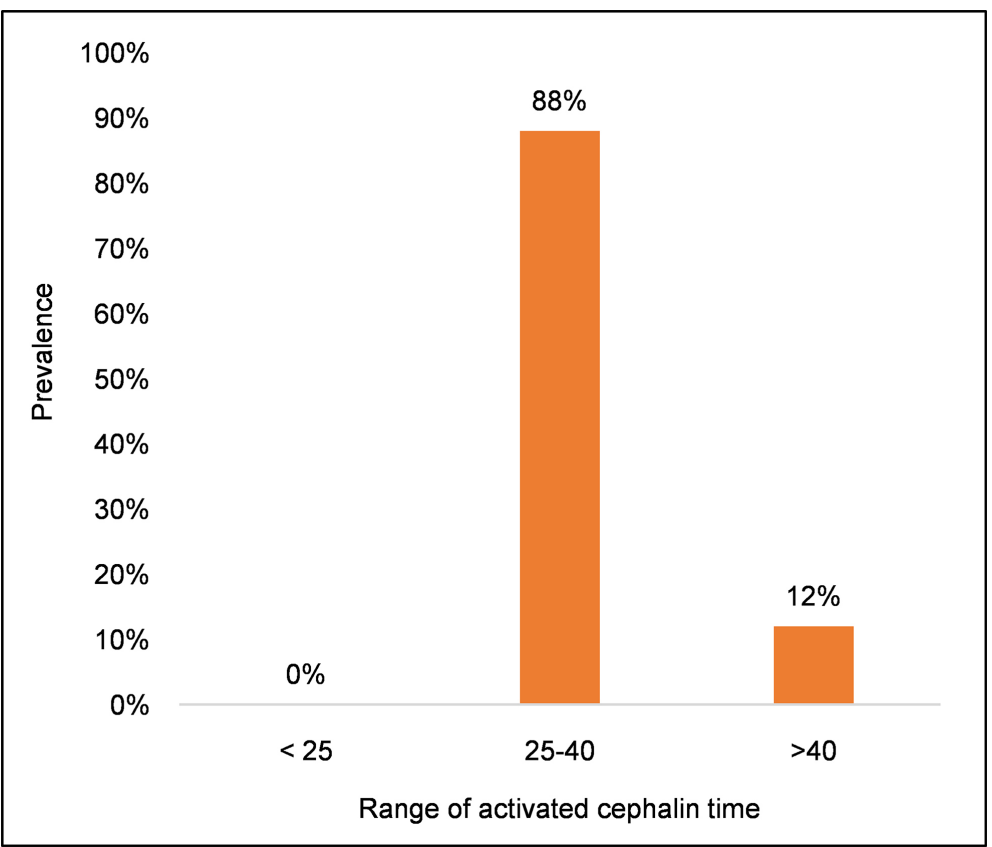

Figure 5. Activated cephalin time of preeclampsia. 


\section{2) Pregnant preeclampsia}

\section{Prothrombin level}

Pregnant women with preeclampsia had a normal ACT of $88 \%$ and an elevated $\mathrm{ACT}$ of $12 \%$.

Pregnant women with preeclampsia were 4.89 times more likely to have hypercoagulability than normal pregnant women (Table 4) and 2.68 times more likely to have hypercoagulability in the general population (Table 5).

\subsection{Comparison of Coagulation Parameters in the Two Groups and Risk Factors for Hypercoagulability}

\section{1) Comparison of biological parameters in the two groups}

Pregnant women with preeclampsia were 4.89 times more likely to develop hypercoagulability than normal pregnant women (Table 4).

Pregnant women with preeclampsia were 2.68 times more likely to develop hypercoagulability in the general population (Table 5).

In linear regression, preeclampsia was significantly associated with prothrombin levels (Table 6).

\section{2) Risk factors associated with hypercoagulability}

We did not find any risk factors associated with hypercoagulability in preeclampsia (Table 7).

Table 4. Comparison of the biological parameters of our population.

\begin{tabular}{|c|c|c|c|c|c|}
\hline Variables & $\begin{array}{l}\text { Preeclampsia } \\
\qquad \begin{array}{c}\mathrm{N}=50 \\
\mathrm{n}(\%)\end{array}\end{array}$ & $\begin{array}{l}\text { Normal pregnant women } \\
\qquad \begin{array}{c}\mathrm{N}=100 \\
\mathrm{n}(\%)\end{array}\end{array}$ & OR & CI & $\mathrm{P}$ \\
\hline \multicolumn{6}{|l|}{ PT (seconds) } \\
\hline Mean \pm standard deviation & $12.13 \pm 1.24$ & $12.53 \pm 0.84$ & & & 0.022 \\
\hline$<12$ & $29(58)$ & $22(22)$ & 4.89 & $2.34-10.20$ & $<0.001$ \\
\hline $12-14$ & $17(34)$ & $78(78)$ & 0.14 & $0.06-0.30$ & $<0.001$ \\
\hline$>14$ & $4(8)$ & $0(0)$ & ---- & ---- & 0.004 \\
\hline \multicolumn{6}{|l|}{ PL (\%) } \\
\hline Mean \pm standard deviation & $100.59 \pm 19.63$ & $93.50 \pm 12.50$ & & & 0.008 \\
\hline$<70$ & $4(8)$ & $0(0)$ & ---- & ---- & 0.004 \\
\hline $70-100$ & $17(34)$ & $78(78)$ & 0.14 & $0.06-0.30$ & $<0.001$ \\
\hline$>100$ & $29(58)$ & $22(22)$ & 4.89 & $2.34-10.20$ & $<0.001$ \\
\hline \multicolumn{6}{|l|}{ ACT (seconds) } \\
\hline Mean \pm standard deviation & $34.08 \pm 4.37$ & $32.98 \pm 3.47$ & & & 0.096 \\
\hline$<25$ & $0(0)$ & $0(0)$ & ---- & ---- & ---- \\
\hline $25-40$ & $44(88)$ & $100(100)$ & 0 & NA & $<0.001$ \\
\hline$>40$ & $6(12)$ & $0(0)$ & ---- & ---- & $<0.001$ \\
\hline
\end{tabular}


Table 5. Comparison of biological parameters of pregnant women with preeclampsia and the total population.

\begin{tabular}{|c|c|c|c|c|c|}
\hline Variables & $\begin{array}{l}\text { Preeclampsia } \\
\qquad \begin{array}{c}\mathrm{N}=50 \\
\mathrm{n}(\%)\end{array}\end{array}$ & $\begin{array}{l}\text { General population } \\
\qquad \begin{array}{c}\mathrm{N}=150 \\
\mathrm{n}(\%)\end{array}\end{array}$ & OR & $\mathrm{CI}$ & $\mathrm{P}$ \\
\hline \multicolumn{6}{|l|}{ PT (seconds) } \\
\hline$<12$ & $29(58)$ & $51(34)$ & 2.68 & $1.39-5.16$ & 0.002 \\
\hline $12-14$ & $17(34.0)$ & $95(63.3)$ & 0.29 & $0.15-0.58$ & $<0.001$ \\
\hline$>14$ & $4(8.0)$ & $4(2.7)$ & 3.17 & $0.76-13.19$ & 0.095 \\
\hline \multicolumn{6}{|l|}{ PL (\%) } \\
\hline$<70$ & $4(8.0)$ & $4(2.7)$ & 3.17 & $0.76-13.19$ & 0.095 \\
\hline $70-100$ & $17(34.0)$ & $95(63.3)$ & 0.29 & $0.15-0.58$ & $<0.001$ \\
\hline$>100$ & $29(58)$ & $51(34)$ & 2.68 & $1.39-5.16$ & 0.002 \\
\hline \multicolumn{6}{|c|}{ ACT (seconds) } \\
\hline$<25$ & $0(0)$ & $0(0)$ & ---- & ---- & ---- \\
\hline $25-40$ & $44(88)$ & $144(96)$ & 0.30 & $0.09-0.99$ & 0.039 \\
\hline$>40$ & $6(12)$ & $6(4)$ & 3.27 & $1.01-10.66$ & 0.039 \\
\hline
\end{tabular}

Table 6. Linear regression analysis of the factors associated with PL, ACT.

\begin{tabular}{|c|c|c|c|c|c|c|}
\hline \multirow{2}{*}{ Variables } & \multicolumn{3}{|c|}{ Prothrombinlevel } & \multicolumn{3}{|c|}{ Activatedcephalin time } \\
\hline & Coefficient & SE & $\mathrm{p}$ & Coefficient & SE & $\mathrm{p}$ \\
\hline Age & 0.03 & 0.02 & 0.175 & 0.01 & 0.05 & 0.761 \\
\hline $\mathrm{BMI}$ & 0.10 & 0.06 & 0.120 & 0.02 & 0.03 & 0.432 \\
\hline Gestationalage & 0.11 & 0.09 & 0.259 & 0.03 & 0.04 & 0.381 \\
\hline Parity & 0.01 & 0.02 & 0.473 & 0.04 & 0.02 & 0.069 \\
\hline Gravidity & 0.02 & 0.01 & 0.286 & 0.02 & 0.01 & 0.226 \\
\hline Preeclampsia & 0.07 & 0.02 & 0.008 & 0.11 & 0.06 & 0.096 \\
\hline
\end{tabular}

SE: Standard Error. 
Table 7. Univariate analysis of risk factors associated with hypercoagulability in preeclampsia.

\begin{tabular}{|c|c|c|c|c|c|}
\hline \multirow[b]{2}{*}{ Variables } & \multicolumn{2}{|c|}{ Prothrombin level } & \multirow[b]{2}{*}{ OR } & \multirow[b]{2}{*}{ CI } & \multirow[b]{2}{*}{$\mathrm{P}$} \\
\hline & $\begin{array}{c}>100 \\
\mathrm{~N}=29 \\
\mathrm{n}(\%)\end{array}$ & $\begin{array}{c}<100 \\
\mathrm{~N}=21 \\
\mathrm{n}(\%)\end{array}$ & & & \\
\hline \multicolumn{6}{|l|}{ Age (years) } \\
\hline$\leq 28$ & $16(55.2)$ & $13(61.9)$ & \multirow[b]{2}{*}{0.75} & \multirow[b]{2}{*}{$0.24-2.38$} & \multirow[b]{2}{*}{0.634} \\
\hline$>28$ & $13(44.8)$ & $8(38.1)$ & & & \\
\hline \multicolumn{6}{|l|}{ Gravidity } \\
\hline $\begin{array}{l}\leq 3 \\
>3\end{array}$ & $\begin{array}{l}22(75.9) \\
7(24.1)\end{array}$ & $\begin{array}{l}15(71.4) \\
6(28.6)\end{array}$ & 1.25 & $0.35-4.48$ & 0.724 \\
\hline \multicolumn{6}{|l|}{ Parity } \\
\hline$\leq 1$ & $\begin{array}{l}18(62.1) \\
11(37.9)\end{array}$ & $\begin{array}{l}10(47.6) \\
11(52.4)\end{array}$ & 1.80 & $0.57-5.61$ & 0.309 \\
\hline \multicolumn{6}{|c|}{ Gestationalage (sa) } \\
\hline $\begin{array}{l}<37 \\
\geq 37\end{array}$ & $\begin{array}{l}18(62.1) \\
11(37.9)\end{array}$ & $\begin{array}{c}8(38.1) \\
13(61.9)\end{array}$ & 2.65 & $0.83-8.45$ & 0.093 \\
\hline \multicolumn{6}{|c|}{ Maritalstatus } \\
\hline Married & $8(27.6)$ & $5(23.8)$ & \multirow[b]{2}{*}{1.21} & \multirow[b]{2}{*}{$0.33-4.44$} & \multirow[b]{2}{*}{0.763} \\
\hline Single & $21(72.4)$ & $16(76.2)$ & & & \\
\hline \multicolumn{6}{|c|}{ BMI $\left(\mathrm{Kg} / \mathrm{m}^{2}\right)$} \\
\hline$<30$ & $14(48.3)$ & $10(47.6)$ & 0.97 & $0.31-2.99$ & 0.963 \\
\hline
\end{tabular}

\section{Discussion}

\subsection{Socio-Demographic and Clinical Characteristics}

\subsubsection{Age}

The mean age of preeclampsia and non-preeclampsia was $27.80 \pm 5.80$ and 29.05 \pm 5.29 , respectively, without statistically significant difference. The extremes were 16 years and 40 years and the group of 25 - 30 years were majority in the two groups matched with respectively $32 \%$ in the preeclampsia and $37 \%$ in the non-preeclampsia. Our findings are similar to the literature data as reported by Awolola et al. in 2016 in Nigeria [7], Han et al. in 2014 in China [13], Chen et al. in 2017 in China [15], Namavar et al. in 2009 in Iran [16] and Nirmala et al. in 2015 in India [17]. The 25 - 30 age group corresponds to the optimal period for human procreation. 


\subsubsection{Obstetric History}

\section{1) Gestation}

The mean pregnancy was $2.66 \pm 1.45$ in the preeclampsia and $2.82 \pm 1.76$ in the non-preeclampsia patients without a statistically significant difference. These results are identical to those found by Namavar et al. in 2009 in Iran [16]. Pauci-gravids were the most prevalent in preeclampsia (40\%) and primi-gravids in non-preeclampsia patients (34\%). These results are contradictory to those found by Nirmala et al. in 2015 in India [17] including 61\% of primi-gravids among preeclampsia. The high number of previous miscarriages in our study may be the explanation.

2) Parity

The mean parity of the preeclampsia was $1.26 \pm 1.30$ and $1.37 \pm 1.42$ in the non-preeclampsia patients without a statistical significant difference. These results are identical to those found by Awolola et al. in 2016 in Nigeria [7]. Nulli-paras were the majority in the two groups, contrary to Han et al. in 2017 in China [13] which found only nulli-paras. This difference can be explained by a conjunction of facts: on one hand the limitation of birth in China due to their overpopulation and our mores on the other hand.

\subsubsection{Gestational Age}

The mean gestational age in preeclampsia patients was $36.16 \pm 3.41$ and $33.43 \pm$ 5.61 in non-preeclampsia patients with a statistically significant difference. These results are identical to those found by Awolola et al. in 2016 in Nigeria [7], Namavar et al. in 2009 in Iran [16] and Nirmala et al. in 2015 in India [17]. This can be explained by the fact that pregnant preeclampsia included were predominant at term.

\subsubsection{The Body Mass Index}

The mean BMI in the two paired groups was $31.16 \pm 4.71$ in the preeclampsia and $30.23 \pm 4.73$ in the non-preeclampsia patients without a statistically significant difference. Our results are contradictory to those reported by Han et al. in 2017 in China [13] who found an average BMI of $23.8 \pm 0.8$ in preeclampsia and $23.4 \pm 1.2$ in non-preeclampsia patients. This difference can be attributable to the racial stature of these studies.

\subsection{Profile of Coagulation Parameters}

\subsubsection{Normal Pregnant}

1) Prothrombin Time/Prothrombin Level

The mean PT was $12.53 \pm 0.84$, this result is identical to that found by Namavar et al. in 2009 in Iran [16] and higher than that found by Chen et al. in 2017 in China [15]. This difference seems to be related to the size of Chen's sample (n $=188$ ). We found a low PT (high PL) of $22 \%$ which is in the same line with those found by Joly B et al. in 2013 [18] and Rosenkranz et al. in 2008 [19]. These results support the physiological hypercoagulability of normal pregnancy. However, these studies did not report the prevalence of increased prothrombin levels in 
this population.

2) Activated cephalin time

The mean ACT was $32.98 \pm 3.47$; this result is identical to that found by Namavar et al. in 2009 in Iran [16] and superior to that found by Chen et al. in 2017 in China [15]. This difference seems to be related to the size of Chen's sample $(\mathrm{n}=188)$. All ACT were normal in our study; our finding is contradictory to the result reported by Thornton et al. in 2010 in Canada [20] who reported a shortening of activated cephalin time due to increased coagulation factors during normal pregnancy. The racial component can explain this difference.

\subsubsection{Pregnant Preeclampsia}

1) Prothrombin time/Prothrombin level

The mean PT was $12.13 \pm 1.24$, this result is identical to that found by Nimarla et al. in 2015 in India [17] and higher than that found by Chen et al. in 2017 in China [15]. This difference may be due to the fact that in the study by Chen et al. the sample size was larger $(n=188)$. Our high PT found at $8 \%$ is superimposable on $6.5 \%$ of Awolola et al in 2016 in Nigeria [7], 10\% of Namavar et al. in 2009 in Iran [16]. The high PT may be explained by the risk of developing disseminated intravascular coagulation (DIC) during preeclampsia and resulting in increased consumption of coagulation factors which appears after a phase of decompensated hypercoagulability. We found a low PT of 58\%; result that we did not find in any of the previous authors. This difference could be linked to the fact that, depending on the calibration of the device used, we had a normal PT value of 12 - 14 seconds, unlike previous studies which used normal values of 11 - 16 seconds. These low PTs (high PL) can be explained by the increase or the excess of the generation of thrombin (increase of fragments 1 and 2 of prothrombin), justifying the hypercoagulability (compensated or not) during the preeclampsia.

2) Activatedcephalin time

The mean activated cephalin time was $34.08 \pm 4.37$; this result is identical to that found by Nirmala et al. in 2015 in India [17] and higher than that found by Chen et al. in 2017 in China [15]. This difference may be due to the fact that in the study by Chen et al the sample size was larger $(n=188)$. The elongated ACT found at $12 \%$ is without comparison to the heterogenous findings of Awolola et al. in 2016 in Nigeria (3.3\%) [7], Namavar et al. in 2009 in Iran (30\%) [16] and Nirmala et al. in 2015 in India (44.4\%) [17]. Prolonged ACT can be explained by the onset of DIC which is one of the complications of preeclampsia resulting in increased consumption of coagulation factors which appears after a phase of decompensated hypercoagulability.

\subsection{Comparison of Coagulation Parameters}

The major hormonal changes in pregnancy are accompanied by changes in the parameters of hemostasis, leading to hypercoagulability [18]. This multifactorial phenomenon, linked to hemodynamic and vascular changes, protects women from hemorrhage which can be fatal at the time of delivery; conversely, these 
changes predispose them to thromboembolic complications [18] [21] [22]. This state of hypercoagulability is described in the literature as being greater in preeclampsia compared to normal pregnancies [10] [11] [12] [13] [23] [24]. In our study we found $58 \%$ of high PT (low PL) in preeclampsia against $22 \%$ in non-preeclampsia patients with an OR of $4.89(\mathrm{p}=0.000)$. The low PT (high PL) was found in $8 \%$ of preeclampsia versus $0 \%$ in non-preeclampsia patients $(\mathrm{p}=$ 0.004). Prolonged ACT was found in $12 \%$ of preeclampsia versus $0 \%$ in non-preeclampsia patients $(\mathrm{p}=0.000)$. In other words, pregnant women with preeclampsia had a higher hypercoagulability compared to pregnant women without preeclampsia in relation to an increase in prothrombin level. These results are in agreement with the literature, in particular, Masson et al. in 2013 in France [12], in a prospective study comparing 103 preeclampsia women to 103 non-preeclampsia control confirmed the significant increase in prothrombin level in preeclampsia women during pregnancy compared to controls. However, these studies did not show the prevalence of increased prothrombin levels in these populations. The hypercoagulability in our study affected only the extrinsic pathway of coagulation. We looked for the risk factors ofhypercoagulability in preeclampsia including maternal age, gestational age and obesity which are identified risk factors for hypercoagulability [19] [25] [26] and we have not found any. This result is identical to the study conducted by Christelle $\mathrm{T}$ et al. in 2014 in France [10]. Thus our results reported in Table VI were not influenced by these identified risk factors. In our total population, we found low pregnancy $(\leq 3)$ as a risk factor for hypercoagulability (OR 2.44; CI 1.09-5.35; $\mathrm{p}=0.026$ ), which did not be reported by the authors aroused. This difference can be explained by the fact that they did not look for pregnancy as a potential risk factor for hypercoagulability in pregnancy. What makes this finding an important contribution.

\section{Conclusion}

At the end of this work, we can conclude that there is hypercoagulability associated with pre-eclampsia, particularly in relation to an increase in the level of prothrombin. The elevated prothrombin level was $58 \%$ in preeclampsia and $22 \%$ in non-preeclampsic patients. The low prothrombin level was $8 \%$ in preeclampsia and $0 \%$ in non-preeclampsia.

\section{Limitation of the Study}

The sample size that was not calculated due to a lack of available data may therefore lack statistical power. The hemostasis parameters used, although not negligible and accessible, seem to us insufficient to assess hemostasis. The particularities of the population studied as well as the individual predisposition to coagulopathy can have a significant impact on the results obtained as well as on their interpretation; and these can explain the different rates between studies and justify their heterogeneity by location. This is the case with some of our findings 
with respect to those of other authors. This therefore means that beyond the thesis-anti thesis approach, it is necessary to consider the racial component sometimes not in phase with certain so-called referential and predominantly Caucasian data. We recruited, consecutively but not exhaustively, 150 pregnant women, including 50 preeclampsia matched with 100 non-preeclampsia.

\section{Contribution of the Authors}

Essome designed the study, collected the data, wrote the manuscript and co-directed the study; Ngaba co-supervised the study, read and corrected the manuscript; Ndom as well as Nana, Boten, Egbe and Halle read and corrected the manuscript; Tocki provided the documentary research as well as the formatting of the manuscript; Foumane led the study and supervised the writing of the manuscript. All authors have read and approved the final version of the manuscript.

\section{Conflicts of Interest}

The authors declare no conflicts of interest regarding the publication of this paper.

\section{References}

[1] Sibai, B., Dekker, G. and Kupferminc, M. (2005) Pre-Eclampsia. Lancet, 365, 785-799. https://doi.org/10.1016/S0140-6736(05)17987-2

[2] ACOG Committee on Obstetric Practice (2002) Practice Bulletin \#33: Diagnosis and Management of Preeclampsia and Eclampsia. Obstetrics \& Gynecology, 99, 159-167. https://doi.org/10.1016/S0029-7844(01)01747-1

[3] Lale Say, D., Chou, D., Gemmill, A., Tunçalp, Ö., Moller, A.-B., Daniels, J., et al. (2014) Global Causes of Maternal Death: A WHO Systematic Analysis. Lancet, 2, E323-E333. https://doi.org/10.1016/S2214-109X(14)70227-X

[4] Fomulu, J.N., Ngassa, P.N., Nong, T. and Nana, N. (2009) Mortalité Maternelle à la Maternité du Centre Hospitalier et Universitaire de Yaoundé, Cameroun: étude Rétrospective de 5 ans (2002 à 2006). Health \& Science, 10, 1-6.

[5] Hladunewich, M., Karumanchi, S.A. and Lafayette, R. (2007) Pathophysiology of the Clinical Manifestations of Preeclampsia. American Society of Nephrology, 2, 543-549. https://doi.org/10.2215/CJN.03761106

[6] Redman, C.W. and Sargent, I.L. (2009) Placental STRESS and Pre-Eclampsia: A Revised View. Placenta, 30, 38-42. https://doi.org/10.1016/j.placenta.2008.11.021

[7] Awolola, O.O. and Enaruna, N.O. (2016) Determination of Coagulopathy Complicating Severe Preeclampsia and Eclampsia with Platelet Count in a University Hospital, South-South, Nigeria. Tropical Journal of Obstetrics and Gynaecology, 33, 179-184. https://doi.org/10.4103/0189-5117.192220

[8] Cunningham, G.F., Leveno, J.K., Bloom, L.S., Hauth, C.J., Gilstrap, L. and Westrom, D.K. (2005) Hypertensive Disorders in Pregnancy. In: Gary Cunningham, F., Leveno, K.J., Bloom, S.L., Spong, C.Y., Dashe, J.S., Hoffman, B.L. and Casey, B.M., Eds., Williams Obstetrics, 22nd Edition, McGraw-Hill Medical Publishing Division, New York, 761-808.

[9] Mackay, A.P., Berg, C.J. and Atrash, H.K. (2001) Pregnancy-Related Mortality from 
Pre-Eclampsia and Eclampsia. Obstetrics \& Gynecology, 97, 533-538. https://doi.org/10.1097/00006250-200104000-00011

[10] Christelle, T., Masson, L., Vermersch, C., Houfflin-Debarge, V., Bauters, A., Bauters, A. and Ducloy-Bouthors, A.-S. (2014) Hypercoagulabilité et Pré-éclampsie: Profil Thromboélastométrique. Anesthésie \& Réanimation, 1, A76.

http://www.docplayer.fr

[11] Devisme, L., Merlot, B., Ego, A., Houfflin-Debarge, V., Deruelle, P. and Subtil, D. (2013) A Case-Control Study of Placental Lesions Associated with Pre-Eclampsia. International Journal of Gynecology \& Obstetrics, 120, 165-168. https://doi.org/10.1016/j.ijgo.2012.08.023

[12] Masson, L., Caron, C., Vermersch, C., Houfflin-Debarge, V., Estevez, M.G. and Ducloy-Bouthors, A.-S. (2013) Phénotype Hypercoagulable et Pré-éclampsie: Etude Prospective de la Génération de Thrombine dans une Population de Patientes Pré-éclamptiques. Anesthésie \& Réanimation, 1, 120-121.

http://www.researchgate.net

[13] Han, L., Liu, X.J., Li, H.M., Zou, J.Q., Yang, Z.L., et al. (2014) Blood Coagulation Parameters and Platelet Indices: Changes in Normal and Preeclamptic Pregnancies and Predictive Values for Preeclampsia. PLOS ONE, 9, e114488.

https://doi.org/10.1371/journal.pone.0114488

[14] Husham, O., Abdel, M., Mohammed, R., Duria, A., Elhassan, M. and Ishag, A. (2016) Fibrinolysis Parameters in Sudanese Women with Severe Preeclampsia. Hypertension in Pregnancy, 35, 559-564. https://doi.org/10.1080/10641955.2016.1211676

[15] Chen, Y. and Lin, L. (2017) Potential Value of Coagulation Parameters for Suggesting Preeclampsia during the Third Trimester of Pregnancy. Am JMedSci, 354, 39-43. https://doi.org/10.1016/j.amjms.2017.03.012

[16] Namavar, J.B. and Rfiee, S.H. (2009) Coagulation Factors in Severe Preeclampsia. Iranian Red Crescent Medical Journal, 11, 321-324.

[17] Nirmala, T., Kumar, P.L., Vani, B.R., Murthy, S.V. and Geetha, R.L. (2015) Study of Coagulation Profile in Pregnancy Induced Hypertension (PIH). Indian Journal of Pathology and Oncology, 2, 1-6.

[18] Joly, B., Barbay, V., Borg, J.Y. and Le Cam-Duchez, V. (2013) Comparison of Markers of Coagulation Activated and Thrombin Generation Test in Uncomplicated Pregnancies. Thrombosis Research, 132, 386-391. https://doi.org/10.1016/j.thromres.2013.07.022

[19] Rosenkranz, H.M., Leschnik, B., Weiss, E.C., Schlembach, D., Lang, U., et al. (2008) Calibrated Automated Thrombin Generation in Normal Uncomplicated Pregnancy. Thrombosis and Haemostasis, 99, 331-337. https://doi.org/10.1160/TH07-05-0359

[20] Thornton, P. and Douglas, J. (2010) Coagulation in Pregnancy. Best Practice \& Research Clinical Obstetrics \& Gynaecology, 24, 339-352.

https://doi.org/10.1016/j.bpobgyn.2009.11.010

[21] Société Française d'Anesthésie et de Réanimation (SFAR), Collège National des Gynécologues et Obstétriciens Français (CNGOF), Société Française de Médecine Périnatale (SFMP) and Société Française de Néonatalogie (SFNN) (2009) Multidisciplinary Management of Severe Pre-Eclampsia. Experts Guidelines 2008. Annales Françaises d'Anesthésie et de Réanimation, 28, 275-281.

[22] Hellgren, M. (2003) Hemostasis during Normal Pregnancy and Puerperium. Seminars in Thrombosis and Hemostasis, 29, 125-130. 
https://doi.org/10.1055/s-2003-38897

[23] Ducloy-Bouthors, A.S. (2010) Hémostase et Pré-éclampsie. Annales Françaises d'Anesthésie et de Réanimation, 29, e121-e134. https://doi.org/10.1016/j.annfar.2010.03.012

[24] Brenner, B. (2004) Haemostatic Changes in Pregnancy. Thrombosis Research, 114, 409-414. https://doi.org/10.1016/j.thromres.2004.08.004

[25] Sultan, P. and Butwick, A. (2013) Platelet Counts and Coagulation Tests Prior to Neuraxial Anesthesia in Patients with Preeclampsia: A Retrospective Analysis. Clinical and Applied Thrombosis/ Hemostasis, 19, 529-534.

https://doi.org/10.1177/1076029612441860

[26] Sharma, S., Uprichard, J., Moretti, A., Boyce, H., Szydlo, R. and Stocks, G. (2013) Use of Thromboelastography to Assess the Combined Role of Pregnancy and Obesity on Coagulation: A Prospective Study. International Journal of Obstetric Anesthesia, 22, 113-118. https://doi.org/10.1016/j.ijoa.2012.12.004 


\section{Annex: Questionnaire}

Hypercoagulability in the context of pre-eclampsia: case-control study at the Laquintinie Douala hospital (Cameroon)

\section{Section 1: Identification}

1) Identification number

2) Age (years)

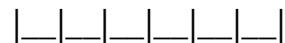

3) Gravidity

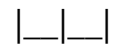

4) Parity

|-

5) Gestational age (Weeks of amenorrhea)

6) Nationality $1=$ Cameroonian $2=$ Stranger

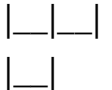

7) Region of origin: $01=$ Far North; $02=$ North; $03=$ Adamawa; $04=$ East; 05 = North-west; $06=$ West; $07=$ Centre; $08=$ Littoral; $09=$ South-west; $10=$ South;

8) Marital status: $1=$ Single; $2=$ Married; $3=$ Widow; $4=$ Separated $/$ Divorced

9) Occupation: $1=$ Housewife; $2=$ Civil servant; $3=$ private; $4=$ student $/$ pupil I_l

Section 2: Past History ( $1=$ yes; $2=$ no; $3=$ don't know $)$

\section{Personal}
1) Preeclampsia
2) Hypertension
3) Diabetes
4) Smoking
5) Thromboembolic disease
|
6) Auto-immune disease
7) Chronic hepatic disease
8) Chronic renal Insufficiency
9) Hematological disease
10) Treatment by anti vitamin $k$

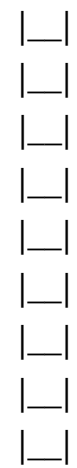

\section{Family}
6) Preeclampsia
7) Hypertension

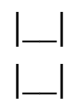

Section 3: Symptoms of Severe Preeclampsia (yes $=1$; no $=2$ ): This section concerns only patients with preeclampsia, if not go directly to section 4
1) Persistent headache
2) Visual disturbances
3) Epigastric pain
4) Vomiting
5) Dyspnea
6) Neurological trouble

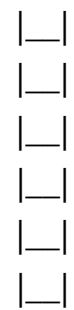

Section 4: Data on Physical Parameters

Anthropometric and Hemodynamic Parameters

1) Weight $(\mathrm{Kg})$ 
2) Height $(\mathrm{Cm})$

|_L___

3) $\mathrm{BMI}\left(\mathrm{Kg} / \mathrm{m}^{2}\right)$

|_-__|

4) $\mathrm{BP}(\mathrm{mmHg})$

Conlusion with Respect to BP

VALUE

$1=\mathrm{BP}$ normal

$2=$ Preeclampsia

SBP

DBP

Proteinuria: This section is reserved to controls

\begin{tabular}{|c|c|c|}
\hline Parameter & Patient value & $\begin{array}{c}\text { Conclusion } \\
1=\text { Significantproteinuria } \\
2=\text { Non-significantproteinuria }\end{array}$ \\
\hline Proteinuria & & \\
\hline
\end{tabular}

Section 5: Data on Hemostasis

\begin{tabular}{|c|c|c|c|c|}
\hline \multirow{2}{*}{ Parametre } & \multirow{2}{*}{ Patient value } & \multicolumn{3}{|c|}{ Conclusion } \\
\hline & & Normal $=1$ & High $=2$ & Low $=3$ \\
\hline \multicolumn{5}{|l|}{ PL } \\
\hline \multicolumn{5}{|l|}{ ACT } \\
\hline \multicolumn{5}{|l|}{ PT } \\
\hline INR & & & & \\
\hline
\end{tabular}

